\title{
Fotografia: da magia à Química-Física
}

\section{Introdução}

$\mathrm{O}$ desejo de registo do real visível conduziu à concepção de inúmeros dispositivos destinados à sua reprodução, Figura 1. A câmara obscura era conhecida desde o renascimento e adquiriu grande popularidade na segunda metade do séc. XVIII, porém, a fastidiosa tarefa de desenhar manualmente as figuras projectadas levou muitos espíritos empreendedores a tentar gravá-las por processos fotoquímicos. Como superfícies fotossensíveis foram utilizadas desde folhas de couve até às mais exóticas mistelas. Assim, obtinham-se reproduções por vezes de boa qualidade que, no entanto, se degradavam rapidamente por exposição à luz.

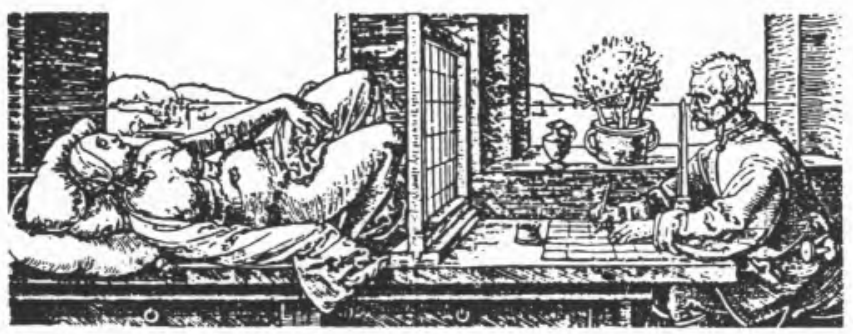

Fig. 1

Um dispositivo de reprodução manual. Dürer

Em 1826, Nicéphore Niepce obtém pela primeira vez uma imagem que se mantém fixa e de tal forma estável que ainda hoje é visível, Figura 2. A técnica desenvolvida por Niepce usava betume da Judeia como substância fotossensível e tem apenas importância histórica. Pouco tempo depois, Louis Daguerre inventa um pro-

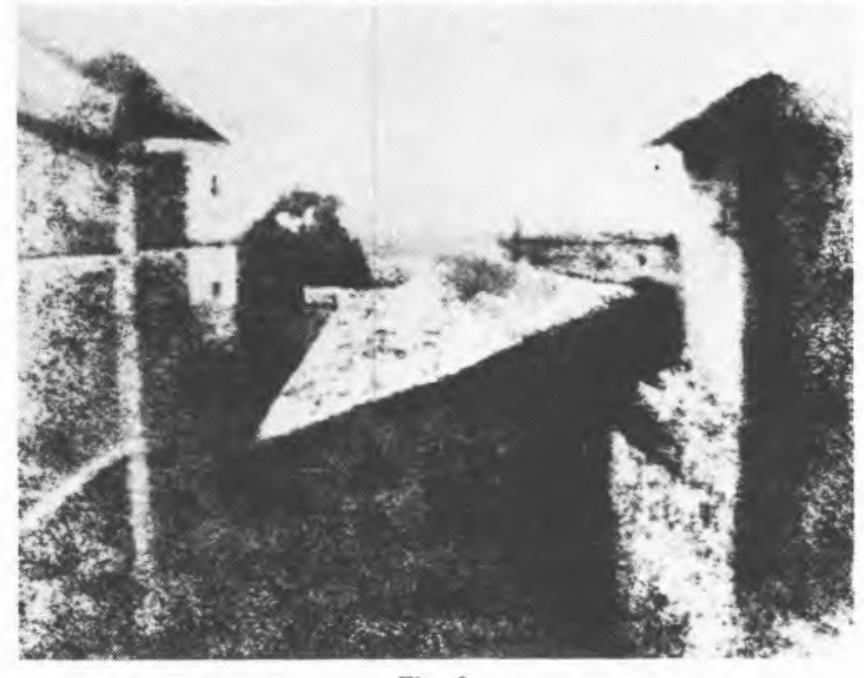

Fig. 2

Julga-se ser esta a primeira fotografia de Niepce - 1826 cesso mais aperfeiçoado baseado na sensibilidade à luz dos sais de prata (iodeto de prata), o Daguerreotipo, de que foi dado conhecimento público em 1839 e que constituiu a primeira técnica fotográfica verdadeiramente prática.

A fotossensibilidade dos sais de prata era há muito conhecida e a sua utilização para obtenção de imagens foi pela primeira vez referida pelo físico alemão Heinrich Schulze, que em 1727 imprime figuras recortadas em cartão opaco sobre cré impregnado de nitrato de prata.

Desde Daguerre até ao aparecimento da Kodak a fotografia foi do foro exclusivo do Photógrapho que necessitava dominar os processos químicos conducentes à prova final. Quando o senhor George Eastman lançou, em 1888, o slogan "- You press the button, we do the rest», tornou acessivel à grande maioria, não familiarizada com as delicadas manipulaçðes que as técnicas da época exigiam, o processo de tomada de vistas. O fotógrafo passou, desta forma, a estar completamente divorciado dos aspectos físico-químicos e o processamento que se desenrola na câmara escura tornou-se saber de apenas alguns iniciados.

\subsection{Descrição sumária do processo fotográfico}

Uma vez que não é suposto que todos os leitores tenham conhecimento dos tratamentos sofridos por uma película desde que entra na máquina até à prova final vamos dar deles um resumo, restrito ao preto e branco, único processo que tentaremos explicar.

As duas peças fundamentais de qualquer máquina fotográfica são a objectiva e a película, Figura 3 . Do nosso ponto de vista, é o que se passa na película que interessa esclarecer. Aquilo a que chamamos película tem hoje o significado de um filme de gelatina sensibilizada por sais de prata aderente a uma folha de plástico. Os dispositivos empregues para a introdução dessa película no interior das máquinas são diversos como é conhecido.

A película saída da máquina, uma vez que é sensível a todos os comprimentos de onda do espectro visível, deverá ser tratada completamente às escuras. Desembaraçada dos seus papéis de suporte ou da bobina que a protege é introduzida num banho relevador após o qual, ainda opaca, já contém bem visível a imagem final. A esta operação que dura cerca de dez minutos segue-se a dessensibilização dos sais de prata não expostos num banho fixador durante alguns minutos. Finalmente, e já à luz, a película é lavada em água corrente para retirar todos estes produtos químicos que,

a Centro de Química Estrutural, Complexo I, Instituto Superior Técnico, 1096 Lisboa Codex. 


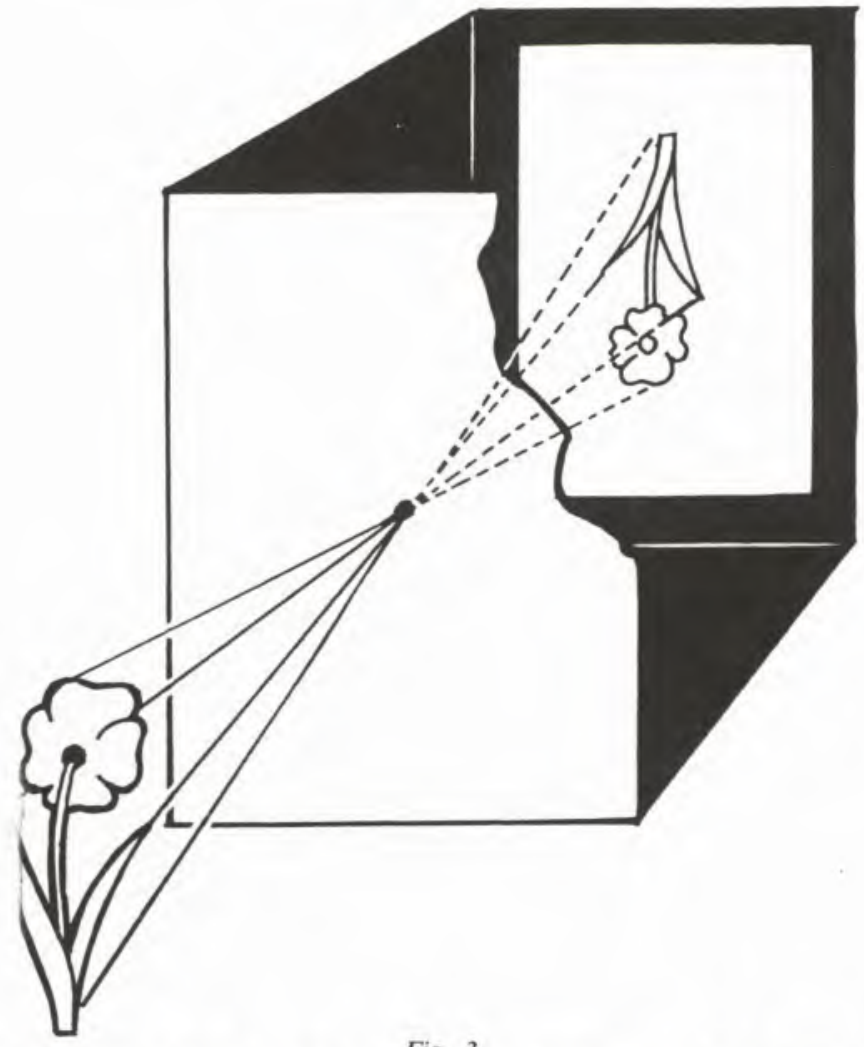

Fig. 3

Representação de uma máquina fotográfica rudimentar de imagem estenopeica

disseminados na gelatina, mais tarde ou mais cedo acabariam por alterar a imagem de prata.

Obtivemos uma imagem negativa, i.e., em que as zonas claras surgem como escuras. Não temos mais que fotografar este negativo tantas vezes quantas quisermos para obter vários positivos. Se nesta fotografia do negativo usarmos novamente pelicula e a tratarmos da forma anteriormente descrita resulta um diapositivo (transparência). Se utilizarmos papel fotossensível e nele projectarmos o negativo ficamos com uma prova em papel. Como a gelatina sensível não difere nas suas características essenciais, na película e no papel, o tratamento a que este é sujeito é idêntico.

Propomo-nos agora analisar os diversos passos deste processo com o rigor que a Química-Física recomenda.

\section{A Química-Física da fotografia}

A compreensão da sequência de tratamentos atrás descrita, a que é sujeita uma superfície sensível desde o estado virgem até se transformar num negativo acabado, envolve o estudo dos seguintes fenómenos:

1) sensibilização da gelatina

2) superfície virgem $\rightarrow$ superfície exposta

3) superfície exposta $\rightarrow$ superfície revelada

4) superfície revelada $\rightarrow$ superfície dessensibilizada

5) superfície dessensibilizada $\rightarrow$ superfície lavada

$\mathrm{Na}$ descrição dos passos referidos preocupar-nos-emos fundamentalmente com os fenómenos químicos e não nos deteremos sobre os delicados problemas tecnologicos que lhes são inerentes.

\subsection{Constituição de uma superfície sensivel}

Como vimos, sobre o filme plástico é espalhada uma camada uniforme de gelatina que contém os sais de prata sensíveis.

\subsubsection{A Gelatina}

A gelatina é apenas um suporte e não tem, em princípio, qualquer papel activo. A sua função é actuar como uma espécie de esponja que suporta a água no meio da qual se vão dar os processos químicos fotográficos - a química fotográfica é uma química de meio aquoso.

A gelatina é uma proteína constituída por cadeias polipeptídicas. $\mathrm{O}$ emaranhado destas cadeias de aminoácidos, coesas devido às ligaçð̄es de hidrogénio que entre elas se estabelecem. deixa muitos interstícios que podem ser ocupados por água formando-se uma estrutura do tipo gel. A introdução de mais água entre as moléculas de gelatina não é energeticamente desfavorável e em meios de elevada força iónica o processo pode atingir tal extensão que as cadeias polipeptídicas percam as ligaçðes que as fixam umas às outras e, como consequência, a gelatina das provas se dissolva. Como os fotógrafos sabem, podem evitar este contratempo, usual em particular nos dias quentes de Verão, fazendo passar a gelatina por um banho endurecedor, uma solução contendo alúmen de crómio, $\mathrm{CrK}\left(\mathrm{SO}_{4}\right)_{2}$, habitualmente um fixador-endurecedor. Os grupos carboxilo existentes nos aminoácidos coordenam-se ao $\mathrm{Cr}^{3+}$ formando ligaçð̄es cruzadas entre as cadeias. Este processo só é eficiente em meio com $\mathrm{pH}>5.5$ que promova a ionização dos grupos ácido. A consequência do baixo $\mathrm{pH}$ na estabilidade do fixador-endurecedor será mais tarde comentada.

\subsubsection{Os Sais de Prata}

Todos os halogenetos de prata, quando na forma de microcristais, são mais ou menos sensíveis à luz. Note-se porém que inúmeros outros compostos sofrem alterações químicas quando absorvem energia luminosa não sendo portanto esta sensibilidade à luz uma magia dos sais de metais preciosos. De facto muitas outras substâncias são fotossensiveis, sendo bem conhecido o exemplo das furocumarinas que, quando expostas à luz solar, se transformam em melanina, veja-se a Figura 4. Acontece porém que as características dos halogenetos de prata os tornam particularmente adequados para o registo de imagens e dificilmente substituíveis por outros processos.
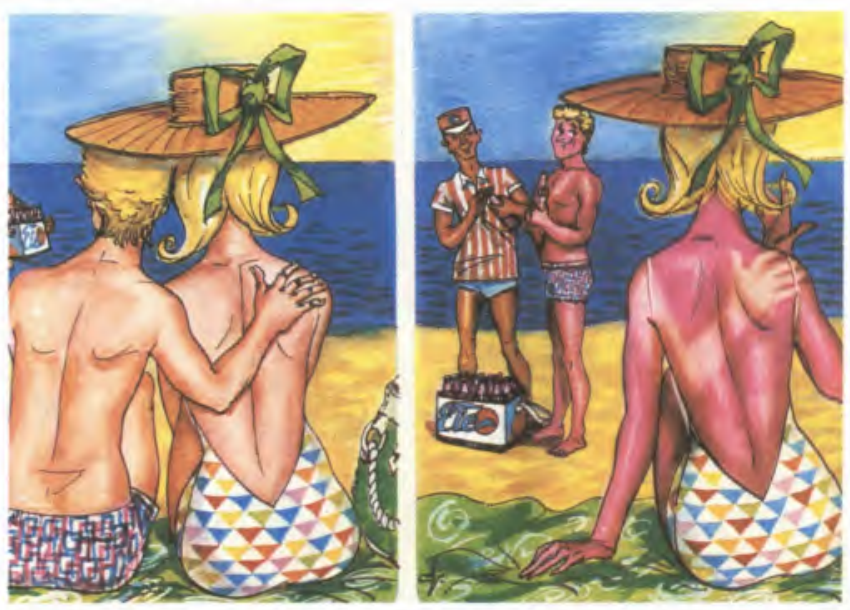

Fig. 4

A transformação das furocumarinas em melanina por acção da luz um conhecido método de obter imagens semipermanentes 
Os halogenetos de prata encontram-se dispersos na fase aquosa do gel de gelatina sob a forma de microcristais com dimensðes médias que, conforme o grau de sensibilidade do material, podem variar de $4 \times 10^{-3} \mathrm{~mm}$ até $2 \times 10^{-6} \mathrm{~mm}$.

A formação destes microcristais dá-se quando a uma solução de gelatina se adicionam, a quente, soluçס̃es de nitrato de prata e de halogeneto de amónio (habitualmente brometo de amónio visto ser o brometo de prata o sal mais usado). O brometo de prata precipita devido à sua baixíssima constante de solubilidade, $\mathrm{K}_{5}\left(25^{\circ} \mathrm{C}\right)=5,2 \times 10^{-13}$.

Os parâmetros estruturais e energéticos destes cristais não são compatíveis com uma interpretação simples em termos do modelo iónico como consequência da relativamente baixa diferença de electronegatividade entre o $\mathrm{Br}$ e a $\mathrm{Ag}$ :

A soma dos raios iónicos $\mathrm{Ag}^{+}$e $\mathrm{Br}$ é de 3,21 Å difere significativamente da distância internuclear de equilibrio experimental, 2,89 $\mathrm{A}$.

$O$ valor calculado de energia recticular para o $\mathrm{AgBr}$, mesmo quando corrigido para as interacções de London, é de $816 \mathrm{~kJ} \mathrm{~mol}^{-1}$, porém o valor experimental retirado do ciclo de Born é de $895 \mathrm{KJ} \mathrm{mol}^{-1}$.

No AgI, por exemplo, já não é a maximização das interacções electrostáticas que controla a estrutura pois, se assim fosse não adquiria a estrutura cristalina da blenda (coordenação 4 do catião) uma vez que a

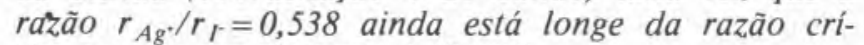
tica para a coordenação 6 (0.414).

Deste modo a ligação química $\mathrm{Br}-\mathrm{Ag}$ deve ser interpretada à luz da teoria das Bandas de Bloch e não através do modelo iónico que se revela insuficiente para a compreensão do processo fotográfico. De acordo com aquela teoria o brometo de prata deve ser encarado com um fotocondutor em que as bandas de valência e condução se encontram separadas de $2,5 \mathrm{eV}$, Figura 5, interpretação esta bem de acordo com os factos experimentais.

Absorção de fotões pelo $\mathrm{AgBr}$

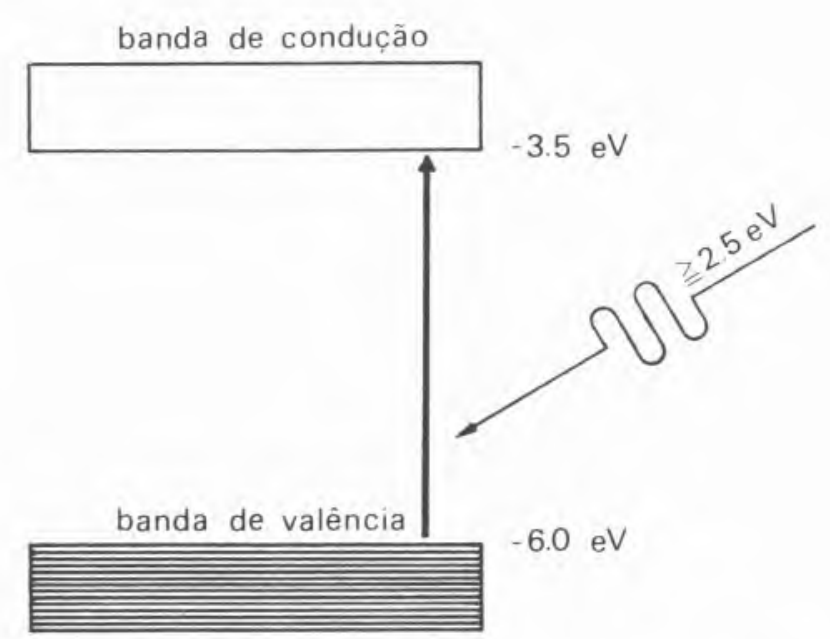

Fig. 5

Uma radiação de energia $\geq 2.5 \mathrm{eV}$ coloca electrões na banda de condução do $\mathrm{AgBr}$
A banda de valência encontra-se completamente preenchida e a energia que a separa da banda de condução corresponde à energia de uma radiação de $4800 \AA$. A diferença de energia de ionização entre o $\mathrm{Br}$ e o $\mathrm{Ag}$ leva a que as orbitais ligantes tenham uma maior contribuição das orbitais atómicas do bromo e as orbitais cristalinas antiligantes maior contribuição das da prata. Desta forma excitar um electrão da banda de valência para a de condução corresponde a retirá-lo de orbitais preponderantemente bromo e colocá-lo em orbitais com elevado carácter prata.

Entre as bandas de valência e de condução surgem niveis de impureza provenientes de átomos estranhos c̀ rede. As impurezas habitualmente existentes tornam o $\mathrm{AgBr}$ um senii-condutor tipo $\mathrm{n}$, facto que, embora importante, não será tido em conta neste texto visto não introduzir interpretaçðes qualitativamente diferentes.

Nos cristais reais as imperfeiçðes da rede, que necessariamente surgem, colocam átomos em situação energeticamente desfavorável. Um átomo de prata nestas condiçðes terá, devido à inadequada geometria, uma dificiente sobreposição das suas orbitais com as do: átomos vizinhos o que leva à formação de orbitais ligantes com menos carácter ligante e de orbitais antiligantes com níveis de energia mais baixa que a dos ní veis mais baixos da banda de condução. Por este moti vo átomos de $\mathrm{Ag}$ em imperfeiçð̃es constituem ratoeira: quer para electrōes quer para lacunas, ratoeiras esta: que são indispensáveis para o processo fotográfico como será visto adiante.

\subsubsection{Tratamentos Finais}

As constantes de solubilidade para os halogenetos $d t$ prata, são tão baixas que podemos supor que par: uma adição estequiométrica não ficam iōes prata o brometo em solução em concentraçð̄es significativa para os processos subsequentes. Porém na fase de pre cipitação do $\mathrm{AgBr}$ é mantido sempre um excesso de $\mathrm{Br}$ não sendo nunca permitido que $\mathrm{o}^{\mathrm{Ag}^{+}}$atinja as propor ções equimolares. Como consequência deste excesso : superfície dos cristais fica parcialmente coberta po: aniðes $\mathrm{Br}$ adsorvidos quimicamente, conferindo-lhe un potencial negativo que aumenta a energia dos electrõe e aniðes na sua proximidade.

Estando os cristais de $\mathrm{AgBr}$ formados ficaram em solu ção os iðes $\mathrm{NO}_{3}^{-}$e $\mathrm{NH}_{4}^{+}$(contraiðes do $\mathrm{Ag}^{+}$e do $\mathrm{Br}$ respectivamente) que serão retirados por lavagem d gel depois de solidificado.

Antes de dar por terminada a preparação da suspensãc sensível esta ainda é submetida a dois tratamentos: 1) digestão do precipitado e 2) introdução de aditivos. A gelatina, após precipitação dos sais sensíveis ma ainda antes de ser lavada sobre o suporte (filme plástico ou papel) é mantida fluida, a quente, durants algumas horas. Ao longo deste período os cristais maiores crescem à custa dos mais pequenos aumentando o tamanho médio em consequência da redução de energia de Gibbs de superfície com a diminuição dé superfície específica do sólido. O processo, natural mente lento devido à baixa constante de solubilidade destes sais é tornado mais eficiente mediante a solubili. zação por complexação do ião $\mathrm{Ag}^{+}$sob a forma d€ $\left[\left(\mathrm{NH}_{3}\right)_{2} \mathrm{Ag}\right]^{+}$.

Como posteriormente veremos, os aditivos, na generalidade sensibilizadores, são fundamentais para as propriedades de qualquer película fotográfica. Incluídos no gel após a digestão do precipitado os sensibilizado 
res químicos aumentam a sensibilidade do sal de prata à radiação absorvida, e os sensibilizadores espectrais permitem que os microcristais absorvam radiaçð̄es a que eles sozinhos seriam transparentes.

A gelatina sensibilizada será então espalhada num suporte no meio de camadas de aderente e anti-abrasivo como se indica na Figura 6.
Notemos que é incorrecta a denominação corrente de emulsão de sais de prata dada à superfície sensível, trata-se antes de um gel em cuja fase aquosa estão dispersos os microcristais de halogeneto de prata; é portanto mais convenientemente designada por suspensão.

Esta película portadora da suspensão sensível pode agora ser introduzida às escuras na máquina fotográfica onde terá lugar o passo seguinte.

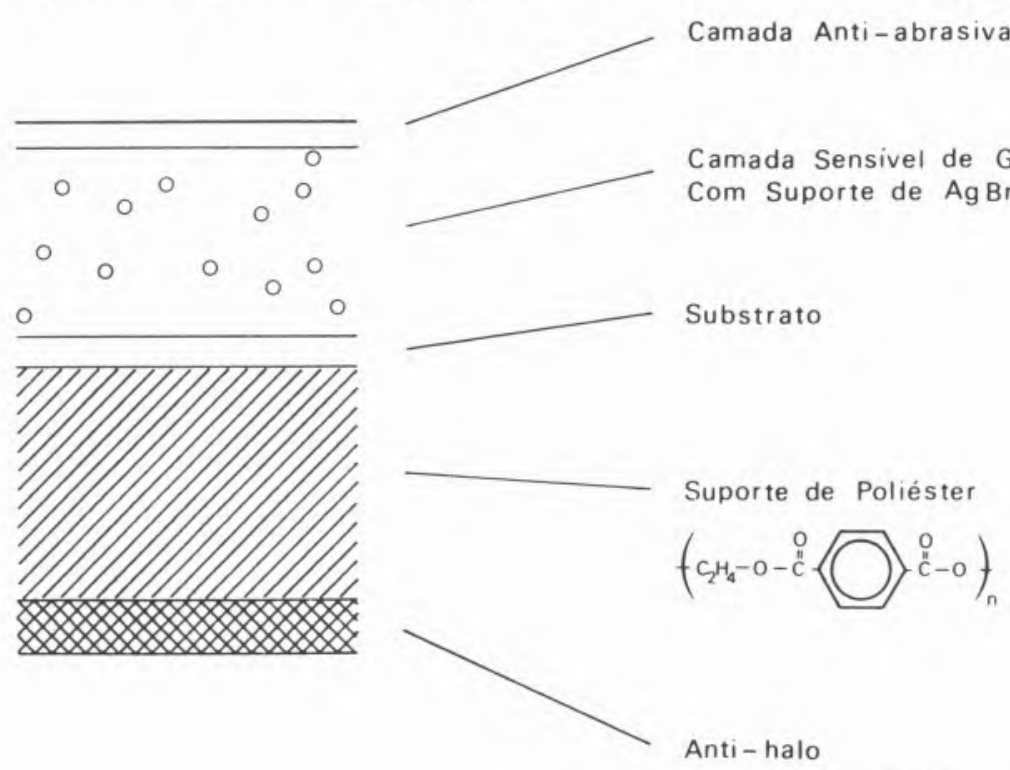

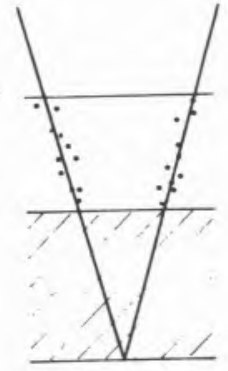

Efeito do Anti-halo

Fig. 6

Seç̧ão de uma película ampliada: a) camadas que compóem a película; b) aç̧ão do anti-halo

\subsection{A formação da imagem latente}

Chegamos ao cerne do processo fotográfico, a formação da imagem latente. Esta, embora invisível à vista desarmada e indetectável mesmo pelos mais poderosos métodos de análise microscópica, manter-se-á durante dezenas de anos inalterável. Os microcristais que receberam luz vão posteriormente reagir, de forma diferente, dos não iluminados, com um agente revelador. Ficaram portanto com propriedades químicas diferentes.

\subsubsection{Mecanismo}

A formação da imagem latente dá-se em dois passos:

$1 .^{\circ}$ - Absorção de um ou mais fotðes pelo microcristal formando pares electrão condutor/lacuna;

$2 .^{\circ}$ - Movimento dos electrð̄es e lacunas no interior do cristal.

Ao absorver um fotão um electrão da banda de valência do $\mathrm{AgBr}$ passa para a banda de condução com formação de uma lacuna na primeira.

A lacuna é atraída para a superfície que, como vimos, contém excesso de $\mathrm{Br}^{\bullet}$ sendo portanto negativa. Uma vez à superfície um ião $\mathrm{Br}^{-}$será oxidado ficando sob a forma radical, $\mathrm{Br}^{+}$, e irá reagir com a gelatina do meio (Figura 7).

O electrão percorre o cristal de ratoeira em ratoeira até encontrar uma mais profunda de onde a probabilidade de sair seja pequena. Constituem ratoeiras átomos de prata intersticiais, superficiais ou quaisquer outros em situação de envolvimento deficiente.

Se electrão e lacuna não se afastam rapidamente $\left(<10^{-9} \mathrm{~s}\right)$, recombinam; perdendo-se portanto para o subsequente processo. Porém dado que a absorção dos fotðes se dá nas primeiras camadas de átomos do cris- tal o potencial negativo da superfície promove a separação electrão-lacuna diminuindo a probabilidade de recombinação.

Cada microcristal absorve algumas dezenas de fotðes. Se pelo menos dois destes se encontrarem em ratoeiras contíguas ou muito próximas ficamos com um grupo de vários átomos de prata ( 2 pelo menos) com excesso de carga negativa relativamente aos restantes depauperados dos seus electrðes pelo $\mathrm{Br}$. Aqueles átomos, deficientes nas suas ligações com o $\mathrm{Br}$, e habitualmente na vizinhança imediata da prata incluída na rede, associam-se a esta formando um agregado metálico que poderá crescer se novos electrōes forem retidos nas proximidades ou neste próprio agregado que entretanto passou a constituir uma ratoeira profunda. Este mecanismo para a formação da imagem latente foi proposto por Gurney e Mott em 1938 e é ainda a descrição do fenómeno que parece estar em melhor acordo com os dados experimentais actualmente disponiveis, equaçðes (1).

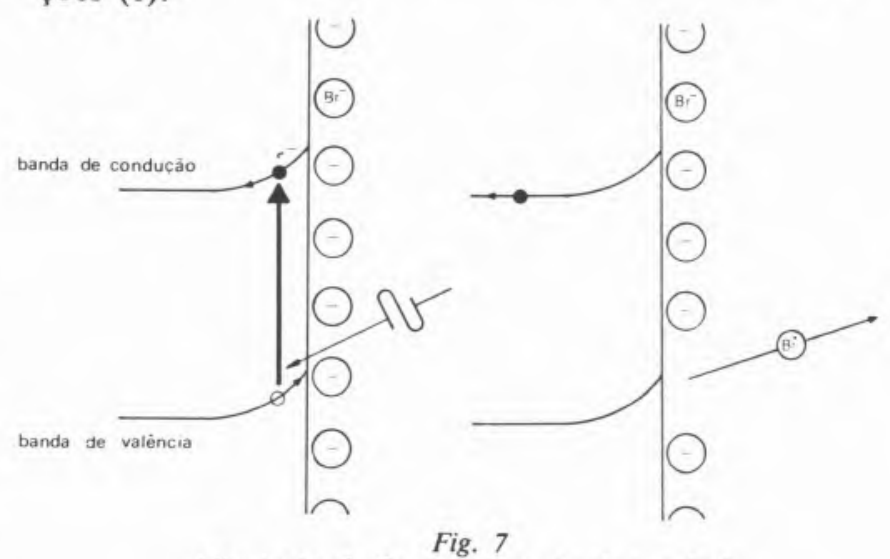

Libertação de Br por absorção de um fotão 
Mecanismo de Gurney Mott:

$$
\begin{array}{ccc}
\mathrm{Ag}^{\circ}+\mathrm{e}^{-} & \text {Ratoeira } \\
\mathrm{Ag}^{-}+\mathrm{p} & \rightarrow \mathrm{Ag}^{\circ}+\mathrm{Br}^{-} \text {Recombinação } \\
\mathrm{Ag}^{-}+\mathrm{Ag}^{+} & \rightarrow 2 \mathrm{Ag}^{\circ} & \\
2 \mathrm{Ag}^{\circ}+2 \mathrm{Ag}^{\circ} \rightarrow 2 \mathrm{Ag}^{\circ} & \text { Espéculo de } \mathrm{Ag}
\end{array}
$$

Estes agregados metálicos estáveis, espéculos de prata, constituem a imagem latente, e aqueles que ficam localizados à superfície vão posteriormente interactuar com o revelador permitindo a transformação de todo o cristal.

Através da sensibilização química aumenta-se a estabilidade dos espéculos de prata que se formam à superfície, aumentando assim a probabilidade de que um cristal fotolisado seja revelável.

\subsubsection{Sensibilização Química}

Os agentes sensibilizadores mais usados são o ouro e o sufureto de prata.

$\mathrm{A}$ adição do ouro, na forma $\mathrm{Au}^{+}$, é feita a seguir à fase de digestão, portanto quando os cristais de halogeneto de prata já estão com as suas dimensões finais, ocupando assim posições superficiais. Como a electronegatividade do ouro é muito elevada provoca uma rarefação de electrōes nos átomos de prata vizinhos tornando-os boas ratoeiras.

O sulfureto de prata, que se forma à superfície dos cristais por reacção dos iões $\mathrm{Ag}^{+}$com um composto com enxofre lábil, por exemplo um tiossulfato introduzido na solução de gelatina, actua de forma semelhante ao ouro.

\subsubsection{Sensibilização Espectral}

$\mathrm{O} \mathrm{AgBr}$ não absorve grande parte da energia do espectro visível como fica claro da Figura 8. Por este motivo, até às últimas décadas do século passado os amarelos e vermelhos não ficavam registados, resultando louras morenas com bocas negras como amoras.

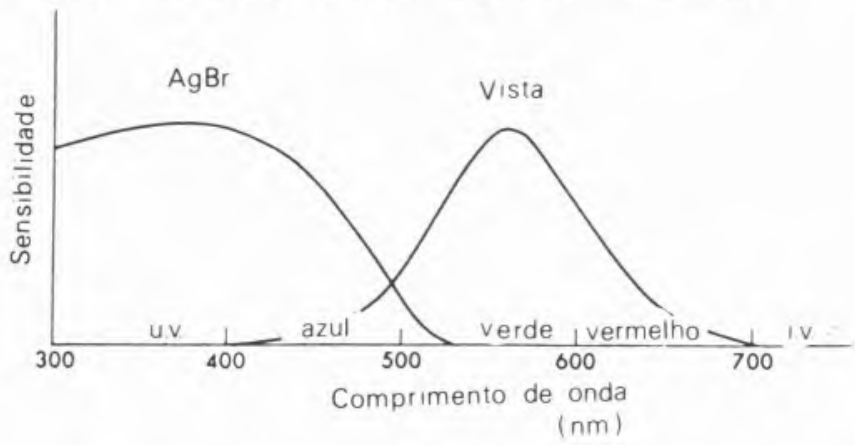

Fig. 8

Comparação entre a sensibilidade do $\mathrm{AgBr}$ e a da vista humana à radiação na gama dos 300 aos $700 \mathrm{~nm}$

O objectivo da fotografia é porém a obtenção de um análogo do real (qualquer que seja o significado que queiramos dar a análogo), portanto nela devem ser registados os objectos visíveis de forma a que o cinzento na prova final reproduza a intensidade relativa da sensação visual provocada pela superfície fotografada, reprodução pancromática.

A película pancromática, com uma sensibilidade semelhante à da vista humana é de fabrico relativamente recente e a sua resposta a comprimentos de onda superiores é conseguida através do processo denominado sensibilização espectral.
Os sensibilizadores espectrais, adicionados à solução após a digestão do precipitado de halogeneto de prata, são corantes que se adsorvem à superfície dos microcristais formando uma monocamada. É a energia absorvida por este corante que vai iniciar a fotólise do sal de prata por um mecanismo que simplificadamente pode ser descrito em dois passos:

$1 .^{\circ}$ - Exitação de um electrão do corante no estado de energia fundamental $S_{0}$ para o estado excitado $S_{1}$; $2 .^{\circ}$ - Transferência deste electrão para a banda de condução do $\mathrm{AgBr}$.

Este mecanismo, esquematizado na Figura 9, é denominado modelo de injecção directa e permite prever com alguma segurança quais os corantes que promovem uma sensibilização eficiente. Assim a energia da LUMO do corante deve ser superior à da mais baixa orbital de condução do sólido.

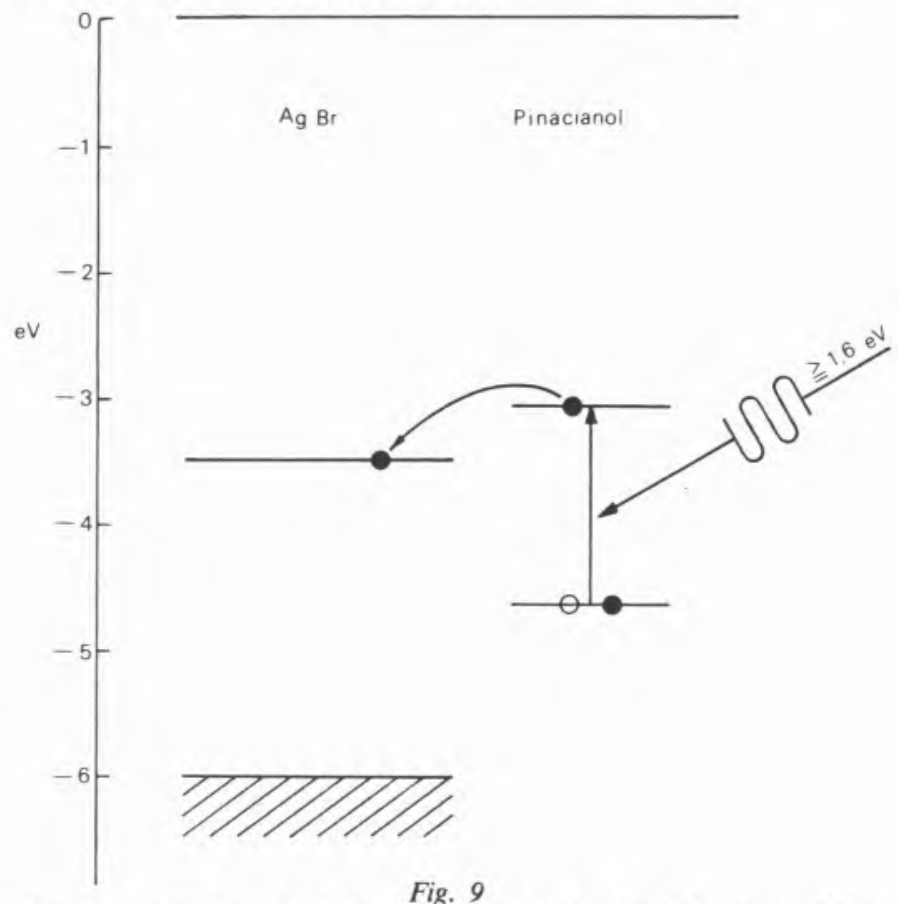

Fotossensibilização do $\mathrm{AgBr}$ pelo pinacianol adsorvido à superfície - Modelo de Injecção Directa

Os corante utilizados são habitualmente cianinas que possuem extensos sistemas $\pi$ e largas bandas de absorção no visível (atribuíveis a transiçðes com carácter de transferência de carga). Por exemplo a diferença entre uma película sem sensibilização cromática - Ilford Line - e um conhecido filme pancromático - Kodak Tri-X Pan - pode ser apreciada na Figura 10, reprodução de uma fotografia a cores da autoria de Milton H. Greeve (1954).

Agora podemos também entender a razão da mefistofélica luz amarelo-esverdeada usada na câmara escura. O papel de ampliação não é sensibilizado, isto é, apenas absorve radiação azul. Pode portanto ser trabalhador sob uma luz que ele não absorve.

\subsubsection{Explicação de algumas características das Emul-} sð̃es Fotográficas com base no mecanismo da formação da imagem latente

\subsubsection{O grão da imagem}

É conhecido o facto de que quanto mais sensível é a película maior a sua granulosidade, diminuindo assim 

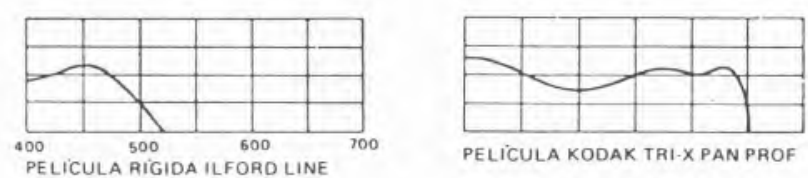

PELICULA KODAK TRI-X PAN PROF
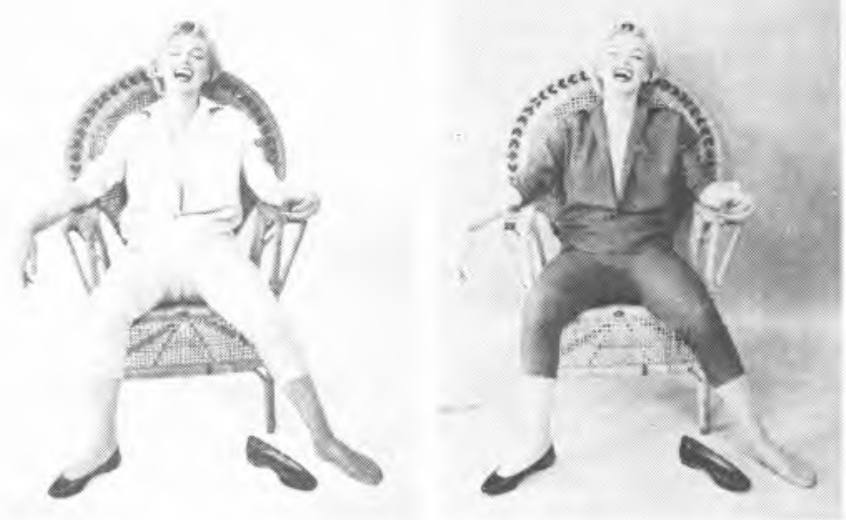

Fig. 10

Comparação entre a Marilyn com e sem sensibilização espectral. Cadeira cor amarelo-verga, roupa em azul-ingénuo, cabelo louro e a beber um elixir amarelo claro

a definição da imagem. A necessidade de aumentar as dimensð̄es dos microcristais para obter películas mais sensiveis é explicável através do mecanismo de formação de imagem latente.

Como vimos, para que um microcristal contendo um agregado de prata metálica seja posteriormente revelável, a prata tem de se dispor à superfície, e para que este agregado seja estável deve agrupar no mínimo quatro átomos. Atendendo a que o rendimento quântico observado é de $40 \%$ cada cristal tem de absorver pelo menos uma dezena de fotðes. Assim, se dois microcristais absorverem cinco fotðes cada, não são reveláveis e os dez fotðes perdem-se. Os cristais maiores, oferecendo maior secção recta à luz incidente, formam portanto uma emulsão mais sensivel.

\subsubsection{Os Desvios à Lei da Reciprocidade}

Se já tentou registar um jantar à luz da vela usando tempos de exposição de alguns segundos, exposição que embora longa é perfeitamente adequada à fixidez dos olhares, se já tentou eternizar aquele luar, então já se lhe depararam os problemas da não reciprocidade. Segundo a lei da reciprocidade (Bunsen-Roscoe) o grau de transformação fotoquímica é proporcional ao produto da intensidade luminosa pelo tempo de iluminação. Desta forma, o decréscimo da intensidade luminosa devia poder ser simplesmente compensado por um concomitante aumento do tempo de exposição. Verifica-se porém que para longos tempos de exposição este procedimento leva a imagens subexpostas portanto a uma diminuição do rendimento quântico do processo. A velocidade com que os fotðes são absorvidos determina o tempo durante o qual um átomo de prata permanece isolado à superfície do cristal. Este é fortemente reactivo e se a velocidade de produção e associação com outros átomos $\mathrm{Ag}^{\circ}$ não competir com a velocidade de desaparecimento por reacção com o meio a imagem latente não se chega a formar.

Não só a lei da reciprocidade não se verifica para baixas intensidades luminosas como também falha nas altas intensidades. Neste caso a concentração de electrôs e lacunas é tão elevadas que a probabilidade de recombinação é muito grande. Por outro lado, formar-se-ão agregados de $\mathrm{Ag}^{\circ}$ internos ao microcristal, imagem latente interna, inúteis sob o ponto de vista fotográfico. $\mathrm{O} \mathrm{Br}^{\circ}$ libertado correspondente a esta prata interna não é eliminado com rapidez suficiente e reage com o $\mathrm{Ag}^{\circ}$ que já se encontra à superfície impedindo a formação da imagem latente superficial.

\subsection{A revelação, ampliação da imagem latente}

Dos microcristais dispersos na gelatina apenas alguns possuem um ou mais espéculos de prata à superfície. Estes verão no banho revelador a sua prata reduzida a $\mathrm{Ag}^{\circ}$, enquanto todos os outros ficarão praticamente intactos. $\mathrm{O}$ banho revelador amplifica portanto a acção da luz sendo o factor de ganho da ordem de $10^{9}$.

É este efeito de amplificação que não tem sido encontrado com outros sais fotossensíveis que torna os halogenetos de prata dificilmente substituíveis no papel de detectores de baixas intensidades luminosas.

Um revelador característico para preto e branco tem a seguinte composição para 11 de água:

Agentes reveladores

Metol (sulfato de N-metil-p-aminofenol)

Hidroquinona(p-dihidroxibenzeno)

Antioxidante Sulfito de sódio

Tampão básico Borax(tetraborato de sódio)

Como é bem de ver, uma mistura destas acrescentada aos compostos já existentes na película forma uma sopa, mais propícia a um tratamento culinário que a uma análise físico-química. De facto a revelação permanece o passo mais difícil de racionalizar.

Trata-se, como é evidente, de uma redução:

$\mathrm{Ag}^{+}+$agente revelador $\rightarrow \mathrm{Ag}^{\circ}+$ agente revelador (forma reduzida) (forma oxidada)

No entanto $\mathrm{o}^{\mathrm{Ag}^{+}}$não tem potencial redox significativamente diferente nos microcristais sensibilizados e nos não sensibilizados.

Quando um papel sensivel exposto é colocado num revelador observa-se, após um período inicial de dormência (cerca de $30 \mathrm{~s}$ ), a formação da imagem que se completa em dois a quatro minutos. Porém se mantivermos o papel dentro do revelador e ao abrigo da luz, 1 a 2 horas depois ele terá escurecido completamente. A única razão para a conversão mais rápida dos microcristais que têm agregados de prata metálica é esta funcionar como catalizador da redução.

\subsubsection{O Agente Revelador}

Os agentes reveladores são usualmente redutores orgânicos, sendo o metol e a hidroquinona em meio básico (pH 9 a 11) os mais vulgarizados.

\section{- Hidroquinona - p-dihidroxibenzeno}

Em meio básico dissocia-se:

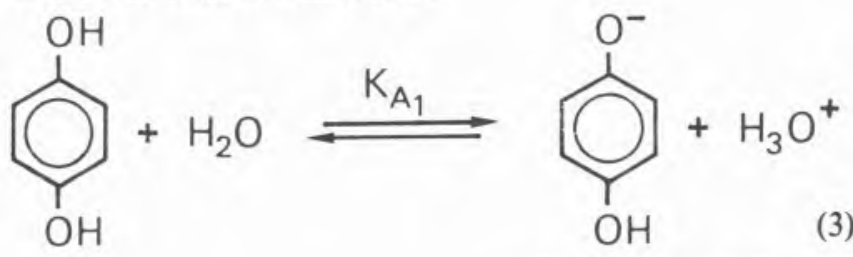

$\mathrm{K}_{\mathrm{al}}=1,2 \times 10^{-10}$ 


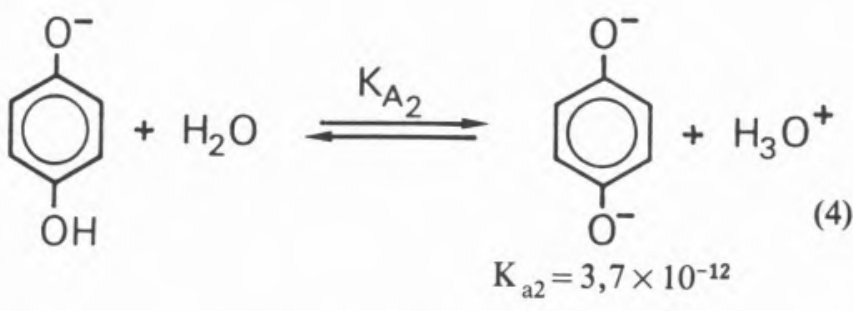

A percentagem de hidroquinona na forma monoionizada, menos activa, em relação à binegativa de mais baixo potencial redox, portanto melhor redutor, é sintonizável por meio do $\mathrm{pH}$. Na Tabela 1 são dados valores de $\mathrm{pH}$ característicos de alguns reveladores.

TABELA 1

Relação entre o pH e as características do revelador

\begin{tabular}{|l|c|c|}
\hline Finalidade do revelador & $\mathrm{pH}$ & "Tampão» \\
\hline Alto contraste & 12,0 & $\mathrm{NaOH}$ \\
Médio contraste & $10,0-10,6$ & $\mathrm{Na}_{2} \mathrm{CO}_{3}$ \\
Grão fino, baixo contraste & $9,4-9,6$ & $\mathrm{Na}_{2} \mathrm{~B}_{4} \mathrm{O}_{7}$ \\
\hline
\end{tabular}

- Metol - sulfato de N-metil-p-aminofenol

També está parcialmente ionizado e é a forma básica o melhor doador electrónico.<smiles>CC=CC=CO[Na]</smiles><smiles>[Y20][WH](=O)Nc1ccc([O-])cc1</smiles>

\subsubsection{O Mecanismo de Redução}

A redução da prata é facilmente conseguida com qualquer dos compostos indicados visto os potenciais redox serem favoráveis. Por exemplo, no caso da hidroquinona: .

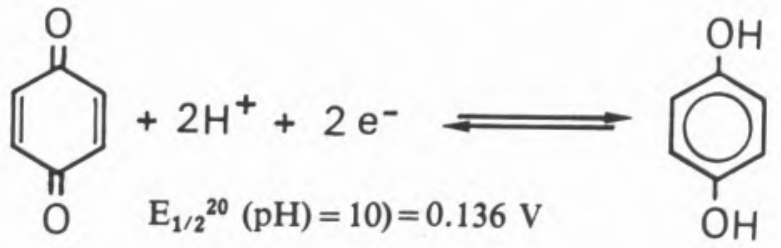

$$
\mathrm{Ag}^{+}+\mathrm{e}^{-} \rightleftharpoons \mathrm{Ag}^{\circ}
$$

$\mathrm{E}_{\mathrm{Ag}^{20}}{ }^{20}=0.799-0.058 \mathrm{pAg}^{+}$
Este processo dá-se, como vimos, preferencialmente nos microcristais expostos. Um dos modelos mais simples para a explicação desta selectividade é o da célula electrolítica.

Tal como é descrito na Figura 11 a prata existente à superfície funciona como duplo eléctrodo colector de electrōes. A zona exposta à solução será o ânodo onde recebe electrôes do revelador aquoso e no cátodo interior fornece-os à prata (I). Globalmente a variação de energia livre não é diferente daquela que foi apresentada acima, porém, funcionando a prata como colector de electrôes a velocidade da transferência global é aumentada, facto que tomaremos aqui sem mais explicação.

Após a introdução do mecanismo da revelação é interessante analisar outros aspectos da química deste processo.
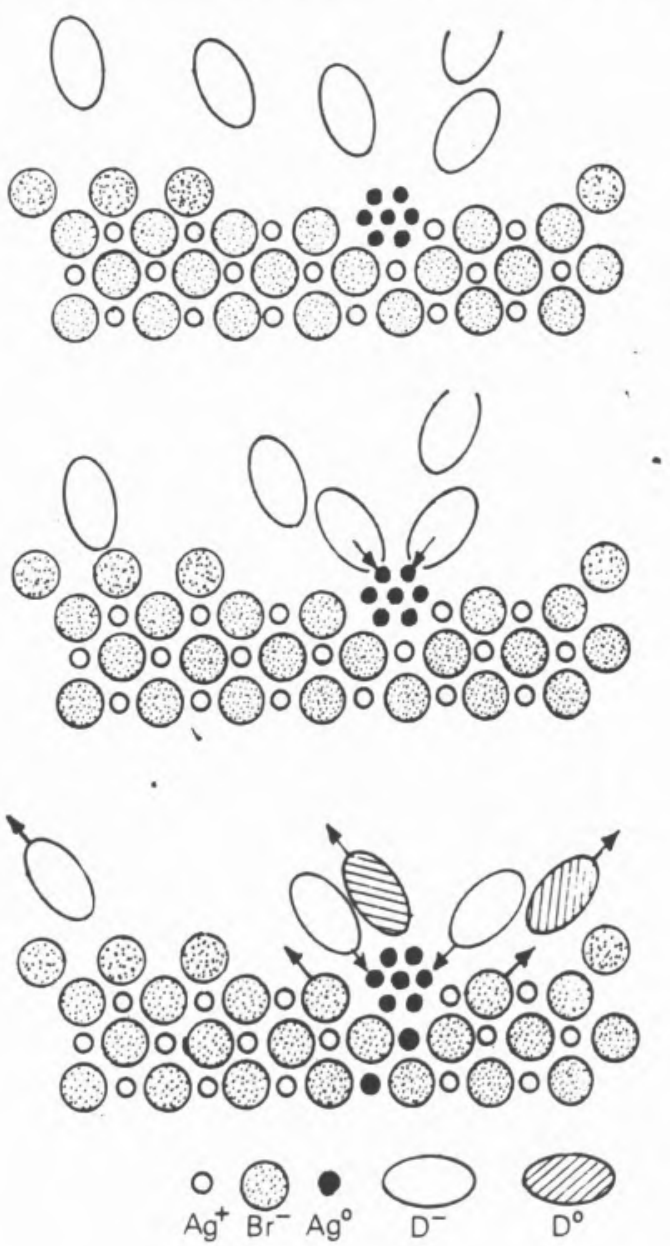

Fig. 11

$O$ centro de revelação funciona como um eléctrodo entre a solução de revelador $e$ o halogeneto de prata

\subsubsection{O Ágente Anti-Oxidante}

Os agentes reveladores em meio básico consomem-se quer por reacção com o oxigénio dissolvido na água quer por polimerização iniciada pelos radicais semiquinona resultantes do passo (9).

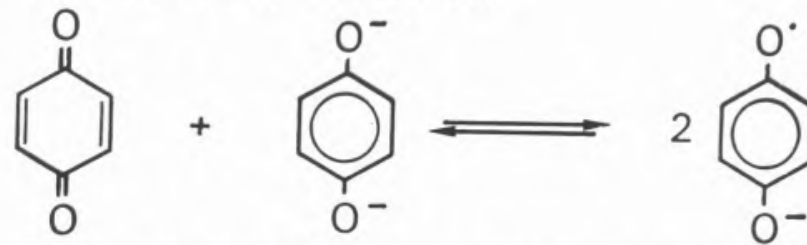

A função do sulfito $\mathrm{SO}_{3}{ }^{2-}$, existente em elevada concentração na solução, é impedir as reacçōes acima quer 
reagindo com $\mathrm{O}_{2}$ dissolvido oxidando-se a sulfato $\left(\mathrm{SO}_{4}{ }^{2-}\right)$, quer inibindo a polimerização da espécie intermediária semiquinona. Na reacção com o sulfito forma-se o ácido hidroquinona monossulfónico ou, após um segundo ataque, o ácido hidroquinona-2,5-dissulfonico. $\mathrm{O}$ derivado monosulfonado ainda pode funcionar como doador electrónico na redução da prata evitando deste modo a degradação rápida do revelador.

\subsubsection{A Superaditividade}

As vantagens da utilização conjunta do metol e hidroquinona num mesmo revelador não residem, como aparece frequentemente escrito na literatura de divulgação fotográfica, em o metol garantir a delicadeza nos meios tons e a hidroquinona a violência dos contrastes. $\mathrm{Na}$ realidade a acção destes dois redutores é cooperativa e a actividade de cada um deles isolado é pequena.
A confusão provém provavelmente de existirem reveladores de alto contraste, fortemente alcalinos e que usam exclusivamente hidroquinona (que assim fica completamente ionizada).

Nos reveladores habituais supøe-se que é o revelador aminado (metol) que reduz a prata e que é de imediato regenerado por oxidação pela hidroquinona, Esquema 1. Este mecanismo, está de acordo com os seguintes factos experimentais:

- Não se nota um decréscimo significativo da concentração de metol durante a revelação;

- A coordenação de azoto à prata costuma ser mais eficiente que a do oxigénio;

- O mesmo tipo de acção (aumento da actividade da mistura em relação à soma dos efeitos dos constituintes) também se verifica noutros pares revelador amino/hidroquinona.

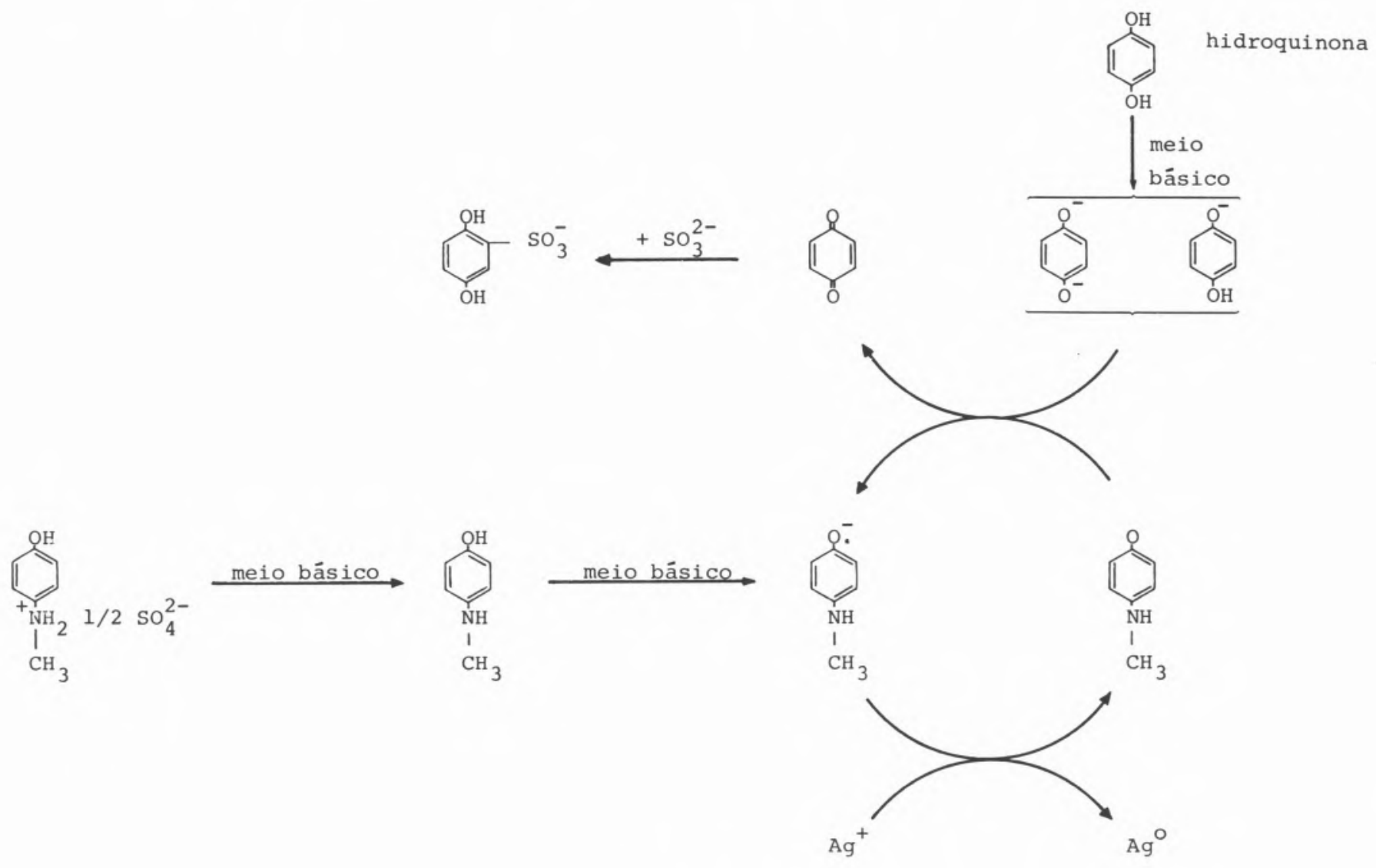

ESQUEMA 1

\subsubsection{O Esgotamento de um Revelador}

Durante a redução de um microcristal de $\mathrm{AgBr}$ o $\mathrm{Br}^{-}$ acumulado na solução reduz a actividade do revelador em parte porque se adsorve à superfície da prata impedindo, por repulsão electrostática, a aproximação de agentes reveladores carregados negativamente, em parte porque desloca o equilíbrio global.

$\mathrm{AgBr}+\mathrm{e}^{-}=\mathrm{Ag}+\mathrm{Br}^{-}$

A acumulação de $\mathrm{Br}^{-}$e/ou a diminuição do $\mathrm{pH}$ tornam a solução reveladora inactiva obrigando à sua substituição.

\subsubsection{Conclusão}

A justificação simples do funcionamento de um revelador metol-hidroquinona apresentada tem sido nos últimos anos questionada e vários outros mecanismos foram propostos. De momento, é um esquema complexo em que a gelatina, desprotonada devido à basicidade do meio, também tem um papel importante que parece concordar com os resultados experimentais existentes.

\subsection{A aç̧ão do fixador}

Estando a imagem revelada quanto baste ainda se 
encontram no meio da gelatina, intactos, todos os microcristais de $\mathrm{AgBr}$ não reduzidos que mantêm a sensibilidade à luz. Nesta altura a revelação deve ser interrompida para evitar que estes também sofram redução. Para isso basta mergulhar a película num banho de água acidificada, banho de paragem, de modo a protonar as formas activas dos agentes reveladores.

A remoção do $\mathrm{AgBr}$ sobrante é feita por complexação do $\mathrm{Ag}^{+}$por tiosulfato $\left(\mathrm{S}_{2} \mathrm{O}_{3}^{-2}\right)$.

$$
\begin{gathered}
\mathrm{Ag}^{+}+\mathrm{S}_{2} \mathrm{O}_{3}^{-2}=\left[\mathrm{Ag}\left(\mathrm{S}_{2} \mathrm{O}_{3}\right)\right]^{-} \\
\beta_{1}=7.14 \times 10^{8} \\
{\left[\mathrm{Ag}\left(\mathrm{S}_{2} \mathrm{O}_{3}\right)\right]^{-}+\mathrm{S}_{2} \mathrm{O}_{3}^{-2}=\left[\mathrm{Ag}\left(\mathrm{S}_{2} \mathrm{O}_{3}\right)_{2}\right]^{-3}} \\
\beta_{2}=2.86 \times 10^{13} \\
{\left[\mathrm{Ag}\left(\mathrm{S}_{2} \mathrm{O}_{3}\right)^{2}\right]^{-3}+\mathrm{S}_{2} \mathrm{O}_{3}^{-2}=\left[\mathrm{Ag}\left(\mathrm{S}_{2} \mathrm{O}_{3}\right)_{3}\right]^{-5}} \\
\beta_{3}=1.85 \times 10^{14}
\end{gathered}
$$

Os oxigénicos do tiossulfato (e não hipossulfito, nome que proveio de um equívoco na estrutura em tempos proposta para este ião), coordenam à prata hibridada em sp ou $\mathrm{sd}_{z^{2}}$ nos complexos do tipo $\mathrm{AgX}$ e em $\mathrm{sp}_{3}$ nos complexos do tipo $\mathrm{AgX}_{3}$.

O mecanismo de dissolução como é sugestivamente apresentado na Figura 12, dá-se em 3 passos. Em primeiro lugar os $\mathrm{S}_{2} \mathrm{O}_{3}{ }^{2-}$ coordenam à prata superficial ficando eles mesmos ligados à superfície do cristal dan-
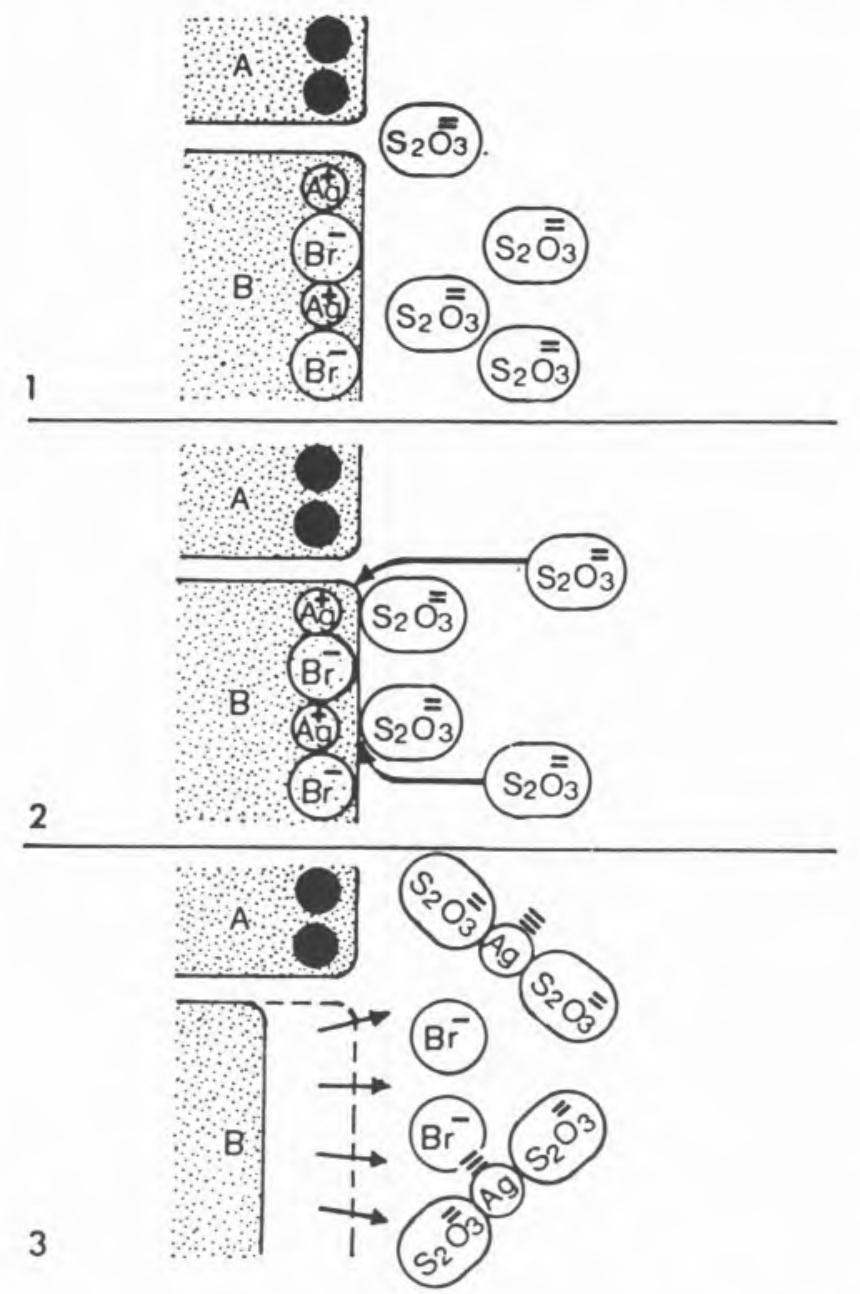

Fig. 12

Acção do fixador separada em passos: (1) o $\mathrm{S}_{2} \mathrm{O}_{3}{ }^{2}$ - liga-se aos iões $\mathrm{Ag}+$ superficiais (2) um segundo ião $\mathrm{S}_{2} \mathrm{O}_{3}{ }^{2}$ - reage com este mesmo $\mathrm{Ag}+$ e (3) o complexo passa para a solução onde pode ainda admitir outro ligando, $\mathrm{Br}$ ou mais um $\mathrm{S}_{2} \mathrm{O}_{3}^{2-}$ do-se a libertação de $\mathrm{Br}^{-}$para a solução. Num segundo passo novos ligandos $\mathrm{S}_{2} \mathrm{O}_{3}{ }^{2-}$ reagem com o mesmo $\mathrm{Ag}^{+}$ solubilizando-se o complexo assim formado. Finalmente, já em solução, pode ou não reagir com outro ligando eventualmente $\mathrm{Br}^{-}$ou $\mathrm{S}_{2} \mathrm{O}_{3}^{-2}$.

A concentração de $\mathrm{S}_{2} \mathrm{O}_{3}{ }^{2-}$ num fixador habitual é elevada $\left(1.5\right.$ a $\left.2 \mathrm{~mol} \mathrm{dm}^{-3}\right)$ de forma a forçar os equilíbrios (11) no sentido dos produtos. Porém a elevada força iónica do meio provoca a ruptura de muitas das ligaçðes de hidrogénio entre as cadeias de gelatina, ligaçð̃es estas que, como vimos, mantêm a rigidez do gel. Corre-se assim o risco de dissolução da gelatina. Já foi referido que se evita este problema introduzindo $\mathrm{Cr}^{3+}$ sob a forma de alúmen de crómio na solução. A $\mathrm{pH}$ maior que 6 , porém, o crómio(III) precipita sob a forma de hidroxido; em contrapartida o tiossulfato é instável em meio ácido, equação 12.

$$
\begin{aligned}
& 2 \mathrm{~S}_{2} \mathrm{O}_{3}{ }^{-3}+4 \mathrm{H}^{+} \rightleftharpoons 2 \mathrm{H}_{2} \mathrm{~S}_{2} \mathrm{O}_{3}=4 \mathrm{H}^{+}+ \\
& \quad+2 \mathrm{SO}_{3}{ }^{2-}+\mathrm{S}_{2}
\end{aligned}
$$

Um dos métodos correntes de evitar a decomposição do tiossulfato consiste em introduzir no meio $\mathrm{SO}_{3}{ }^{2-}$, por exemplo, adicionando sulfito de sódio. Desta forma o equilíbrio (12) é deslocado no sentido dos reagentes. Uma fórmula característica de fixador-endurecedor é a seguinte:

Ferrania F9 (1 1 de solução)

Tiossulfato de sódio

$400 \mathrm{~g}$

Sulfito de sódio $30 \mathrm{~g}$

Sulfato de crómio e potássio (alúmen de crómio) $24 \mathrm{~g}$

Ácido sulfúrico concentrado

$5 \mathrm{ml}$

\subsection{A lavagem final}

Saida do banho fixador a gelatina vem impregnada de sais solúveis. Estes, embora estáveis, acabariam por deteriorar a gelatina e a imagem de prata. É portanto conveniente eliminá-los lavando com água a película. Porém no início da lavagem é retirado o excesso de $\mathrm{S}_{2} \mathrm{O}_{3}{ }^{2-}$ o que provoca o deslocamento do equilíbrio (11) para a esquerda com formação de $\mathrm{Ag}^{+}$. Se este último não for completamente extraído por uma lavagem longa ficará disperso no gel e será mais tarde reduzido ou atacado. Conclui-se portanto que é preferível não lavar a película a lavá-la deficientemente.

A efíciência da lavagem também fica comprometida por uma fixação incompleta. Como vimos, o primeiro passo de ataque do fixador é a formação de $\left[\mathrm{Ag}\left(\mathrm{S}_{2} \mathrm{O}_{3}\right)\right]^{-}$ainda ligado à superfície do cristal pelo átomo de prata. Esta forma é portanto insolúvel e a decomposição posterior do tiossulfato dá origem a compostos de enxofre que atacam a imagem de prata.

\section{Bibliografia}

(1) H.J. WALlS, G.G. ATTRIDGE «Basic Photo Science: How Photography Works» ed. 2, Focal Press Ld., London, 1977.

Um tratado dirigido ao não químico mas de leitura agradável e proveitosa mesmo para o químico.

(2) M.R. SAHYUN, "Mechanisms in Photographic Chemistry» J. Chem. Educ., 51 (1974) 72.

(3) A Royal Photographic Society of Great Britain edita um jornal, "The Journal of Photographic Science", indispensável para seguir os últimos avanços em química-física da fotografia.

(4) H. MEIER, "Photosensitization on Inorganic Solids", Photochem. Photobiol., 16 (1972) 219.

Importante artigo de revisão sobre fotosensibilização. 